\title{
Prevalence of adult eczema, hay fever, and asthma, and associated risk factors: a population-based study in the northern Grassland of China
}

\author{
Xiaoyan Wang ${ }^{1,2}$, Yan Zhuang ${ }^{1,2}$, Yanlei Chen ${ }^{1,2}$, Hongtian Wang ${ }^{1,2}$ and Xueyan Wang ${ }^{1,2^{*}}$
}

\begin{abstract}
Background: There has been research about the prevalence and risk factors of eczema, hay fever, and asthma in children, but little is known about these conditions in adults in China.

Objectives: To explore the prevalence of adult eczema/atopic dermatitis (AD) and its risk factors in northern China.

Methods: A cluster sampling randomized population-based survey was conducted using a face-to-face questionnaire combined with skin prick tests of ten common aeroallergens including nine pollen allergens and Dermatophagoides pteronyssinu (Dp) allergen. The questionnaire was designed by specialists and included questions on the prevalence of eczema, hay fever, and asthma, socioeconomic risk factors, family history of atopy and environmental exposures. The prevalence of eczema with asthma and/or hay fever (EAH) was applied as a proxy of AD in this study.

Results: Overall, 2096 subjects were enrolled and completed the study. The prevalence of eczema was 15.7\% (95\% Cl 14.3-17.4), while the prevalence of hay fever and asthma were $20.6 \%(95 \% \mathrm{Cl} 18.9-22.4)$ and $6.5 \%$ (95\% Cl 5.5-7.6), respectively. In particular, the prevalence of EAH was $5.1 \%(95 \% \mathrm{Cl} 4.4-7.0)$. The prevalence of eczema and EAH was significantly associated with younger age, atopy family history, high education level, urbanization, and antibiotic overuse $(P<0.05$, logistic regression). The sensitization rate was higher in EAH compared with eczema (48.2\% vs $41.0 \%$, $P=0.018$ ), with weed pollen sensitization being the most common. Subjects with two or more concomitant allergic diseases had increased risk of eczema and EAH $(P<0.001)$. Allergen sensitization increased the risk of eczema and EAH $(P<0.001$, both).
\end{abstract}

Conclusions: Adult eczema and EAH are prevalent in northern China under high pollen exposure. Socioeconomic and environmental factors affected the prevalence of adult AD in China. Dp had a particular impact on the prevalence of eczema/AD in the grassland region.

Keywords: Eczema, Atopic dermatitis, Socioeconomic status, Risk factors, Allergen sensitization

*Correspondence: allergy_wxy@126.com

${ }^{1}$ Department of Allergy, Beijing Shijitan Hospital, Capital Medical University, No. 10, Tieyi Road, Haidian District, Beijing 100038, China

Full list of author information is available at the end of the article

\section{Introduction}

Atopic dermatitis (AD) is a chronic, inflammatory cutaneous disorder that typically begins in early childhood, with a prevalence of $7-10 \%[1,2]$. AD is associated with several comorbidities and clinical manifestations such as skin lesions that profoundly

c) The Author(s) 2021. This article is licensed under a Creative Commons Attribution 4.0 International License, which permits use, sharing, adaptation, distribution and reproduction in any medium or format, as long as you give appropriate credit to the original author(s) and the source, provide a link to the Creative Commons licence, and indicate if changes were made. The images or other third party material in this article are included in the article's Creative Commons licence, unless indicated otherwise in a credit line to the material. If material is not included in the article's Creative Commons licence and your intended use is not permitted by statutory regulation or exceeds the permitted use, you will need to obtain permission directly from the copyright holder. To view a copy of this licence, visit http://creativeco mmons.org/licenses/by/4.0/. The Creative Commons Public Domain Dedication waiver (http://creativecommons.org/publicdomain/ zero/1.0/) applies to the data made available in this article, unless otherwise stated in a credit line to the data. 
alter quality of life in adults [3]. AD has been associated with anxiety, depression and suicidal ideation and imparts a large burden in terms of both reduced work productivity and increased global health care expense $[4,5]$.

Traditionally, AD is considered a disease of childhood that remits in adolescence and adulthood $[2,6]$. Although $60-75 \%$ eventually outgrow AD with age, some continue to experience $\mathrm{AD}$ symptoms in adulthood [6-8]. Furthermore, one in four adults with $\mathrm{AD}$ report adult-onset disease [6,8]. Globally, most studies focus on the prevalence of $\mathrm{AD}$ in children [4, 9-15]. Surprisingly, few studies looked at the epidemiology of AD in adults. Studies in the US, Europe, Japan, Italy, and Sweden demonstrated varying disease prevalence, showing a lower prevalence of adult AD compared with childhood AD [16-18] However, few such studies have been conducted in China. Adult AD usually deviates from the classic pattern of childhood AD, and is associated with distinct risk factors, clinical feature, associated risk factors, genetics, and comorbidities. Epidemiologic studies are needed in adult populations to determine the features of adult AD.

The diagnosis of adult AD is challenging [19, 20]. The clinical criteria of $\mathrm{AD}$, such as the Hanifin and Rajka criteria, are impractical for large-scale surveys. Other criteria, such as the UK Working Party criteria, Japanese Dermatological Association criteria, and Eczema Prevalence Impact Working Group diagnostic criteria, were also applied in different surveys $[6,21]$. Due to the inability to accurately diagnose AD across a large population in a cost-effective way, the diagnosis of adult $\mathrm{AD}$ requires standard criteria. In recent years, the comorbidity of atopic diseases (asthma and/or hay fever) with eczema have been defined as EAH and was employed in several epidemiological studies to represent $\mathrm{AD}[17,22]$. Each definition captures a different subset of the eczema/AD disease spectrum, and therefore both definitions were included in our population-based study.

The prevalence of childhood AD is reported to be 2.5$12.94 \%$ in China [23-25]. To our knowledge, there are no recent studies on adult $\mathrm{AD}$ in China. The aim of this study was to explore the prevalence and determinants of adult eczema/AD in the northern grassland region of China using data obtained from a face-to-face questionnaire. The clinical data we obtained from this survey provide information such as risk factors and allergic sensitization status of adult $\mathrm{AD}$ in a region under high pollen exposure according to EAACI's definition [26] and our prior study [27]. This information provides advice regarding lifestyle and prevention of adult $\mathrm{AD}$ in this region.

\section{Methods}

\section{Study design}

A multistage, clustered, stratified survey was carried out in the northern grassland of China from May to August of 2015 (Fig. 1). The timeline was alos the pollen season locally. The study was designed by a group of epidemiologists. The geographic location of survey activity is found in Fig. 2. The Xilingol and Horqin grasslands, which are located in the eastern and middle part of the Inner Mongolia Autonomous Region of China, were included, and six study regions (Erenhot, Xilinhot, Duolun, Jarud, Kailu, and Tongliao) were selected (Fig. 2). The survey was conducted by the same team sequentially to maintain the uniformity. The interviewers consisted of specialists and nurses who were trained before the investigation. The participants were chosen by random clustering method and informed at least two weeks earlier either by a letter or by a telephone call by local coordinators or healthcare officers. All subjects from the selected clusters were invited to finish this study.

\section{Questionnaire data}

All subjects received a face-to-face interview conducted by trained specialists using a standard questionnaire. The questionnaire included demographic information such as age, gender, ethnic group, place of residence, education level, socioeconomic status, family income, and body mass index (BMI). Data regarding allergic disorders (hay fever, conjunctivitis, asthma, food allergy, and drug allergy) and concomitant chronic diseases, family history of atopy, and environmental risk factors were also collected. The questionnaire was double-checked and re-answered if the quality was

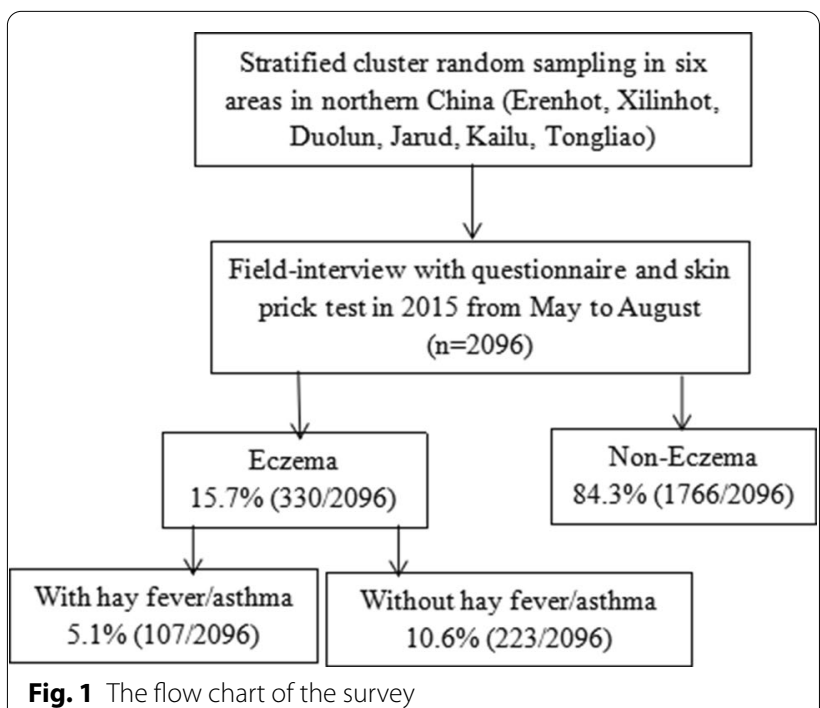




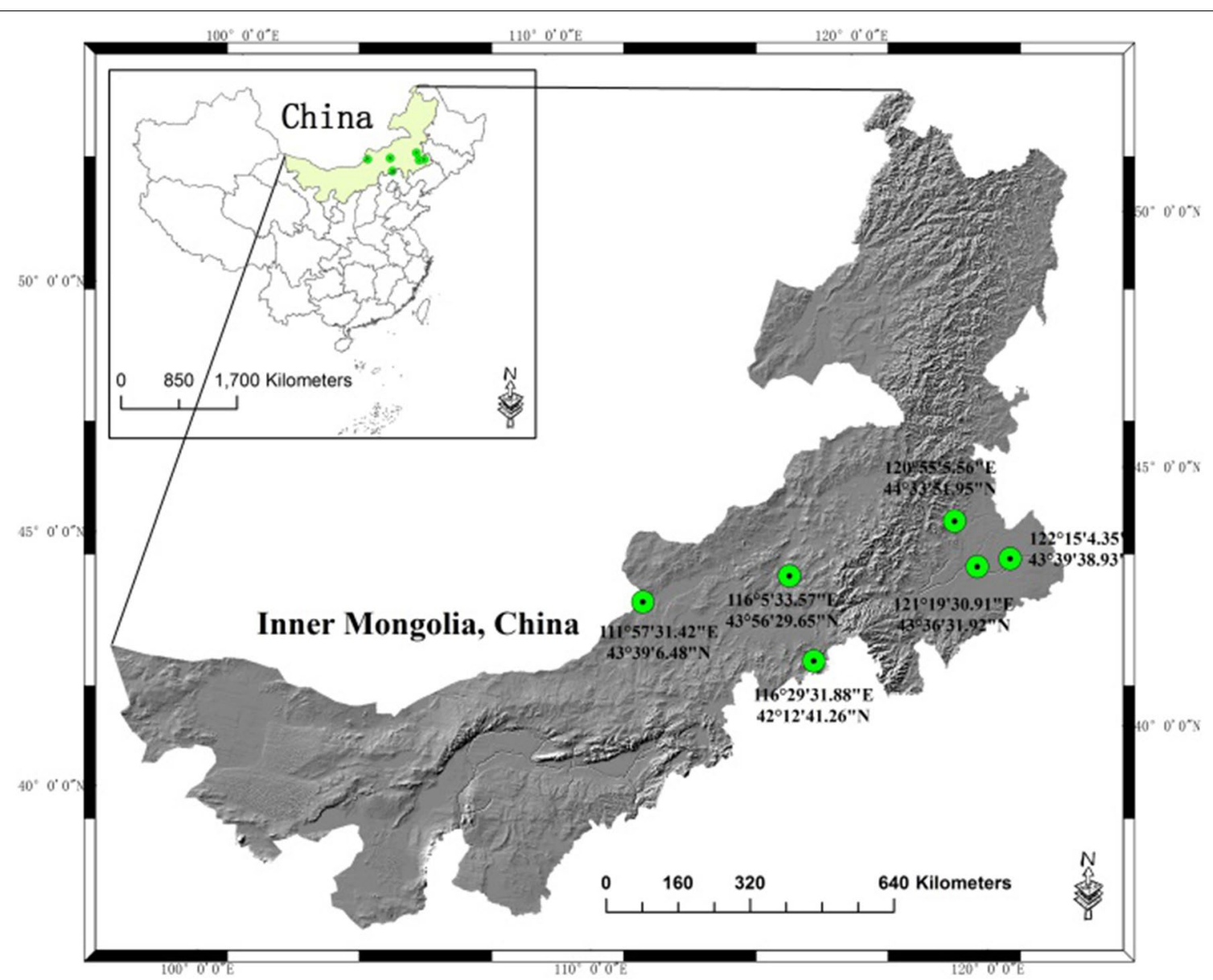

Fig. 2 Geographic locations of the study sites, including the Erenhot, Xilinhot, Duolun, Tongliao, Jarud, and Kailu areas of northern China

unsatisfactory. All participants signed informed consent. For those $<18$ years, informed consent was signed by their parents or guardians. Approval to conduct this study was granted by the institutional review boards of Beijing Shijitan Hospital, the affiliated hospital of the Beijing Capital Medical University (2015 No. 3).

\section{Disease definitions}

Eczema was defined as a positive response to the following questions: "During the past year, have you had dermatitis, eczema, or any red, inflamed skin rashes?" or "Have you been diagnosed with eczema or dermatitis by a dermatologist during past year?" or typical eczema rashes were found on the study participants.

Hay fever was defined as a positive response to the following questions: "During the past year, have you been diagnosed with hay fever by a doctor or health professional?" or "Did you have at least two of the four common symptoms (itchy nose, sneezing, runny, and blocked nose) for at least one hour on pollen days during the past year?".
Asthma was defined as a positive response to the following question: "Have you been diagnosed with asthma by a physician during the past year?".

Subjects who were reported to have eczema combined with asthma and/or hay fever were defined as having EAH as published $[15,16,21]$. EAH has been used to represent $\mathrm{AD}$ in previous studies.

\section{Skin prick test}

All participants received skin prick tests (SPTs) of the ten common aeroallergens in the northern grassland region, which were determined by a combination of pollen monitoring and our preliminary study [27]. The ten common aeroallergens were: Artemisia (Ar); Betula (Be), Chenopodium (Ch); Humulus scandens (Hu); Salix (Sa); Zea mays (Ze); Juniperus (Ju); Ulmus pumila (UI); Populus (Po), and Dermatophagoides pteronyssinus $(D p)$. Standardized allergen extracts (Macro-Union Pharmaceutical Lim, Beijing, China) were applied. Antihistamines and other related medications were restricted at least three days prior to SPT. SPT was 
performed by experienced nurses following a standard protocol [28]. The drop of aeroallergen was placed on the flexor side of the forearm, and then the central part of the allergen was pricked using a sterile skin prick needle. The puncture depth was restricted to the epidermis. The distance between each allergen was $2 \mathrm{~cm}$. Histamine and saline were applied as positive and negative controls, respectively. The results were evaluated $15 \mathrm{~min}$ after the procedure. A wheal diameter $\geq 3 \mathrm{~mm}$ was regarded as positive, whereas $<3 \mathrm{~mm}$ was considered negative. In addition to analyze the severity of sensitization, a positive score ranged from class 1 to class 4 was defined based on the wheal size. Class 1: a wheal diameter between 3 and $5 \mathrm{~mm}$; Class 2: a wheal diameter between 5 and $10 \mathrm{~mm}$; Class 3: a wheal diameter between 1 and $2 \mathrm{~cm}$; Class 4: a wheal diameter $\geq 2 \mathrm{~cm}$ and present with pseudopods.

\section{Covariates and confounders}

The covariates in this study were recorded from the questionnaire. Socioeconomic factors: gender; age group; education status (primary education, high school education, or graduated from college or university); family income; and BMI, with BMI $<25 \mathrm{~kg} / \mathrm{m}^{2}$ defined as lean or healthy, BMI between 25 and $29 \mathrm{~kg} / \mathrm{m}^{2}$ defined as overweight, and $B M I \geq 30 \mathrm{~kg} / \mathrm{m}^{2}$ defined as obese. Environmental risk factors: current smoking status (nonsmoker, smoker, ex-smoker), pet keeping, heating mode (wood, coal, or central heating), overuse of antibiotics ( $>3$ times/year), and outdoor activity ( $\leq 1 \mathrm{~h}, 2-3 \mathrm{~h}, \geq 4 \mathrm{~h}$ ).

\section{Statistical analyses}

Data were processed and analyzed with IBM SPSS Statistics for Windows Version 23.0 (IBM Corp, Armonk, NY, USA) by a professional biostatistician. Categorical data ware described as numbers and percentages. Continuous data are shown as mean \pm standard deviation (SD). Differences between groups in subject characteristics were tested using a $t$ test or Wilcoxon rank-sum test for continuous variables, and chi-square or Fisher exact test was used for categorical variables. The Bonferroni correction was performed to correct $P$ values of multiple pairwise comparisons. Multivariate logistic regression analysis was performed to explore the risk factors related to adult eczema and estimate their odds ratios. All tests were two-sided with a significance level of 0.05 .

\section{Results}

\section{Prevalence of adult eczema and hay fever/asthma}

A total of 2096 adults in six regions of the northern grassland of Mongolia were enrolled and completed the study. There were 850 (40.5\%) male and 1246 (59.5\%) female subjects in the study cohort. Overall, 330 subjects were found to have eczema, with a prevalence of $15.7 \%$ (95\% CI 14.3-17.4, Table 1). The prevalence of hay fever was $20.6 \%$ (95\% CI 18.9-22.4) among individuals with eczema, and 6.5\% (95\% CI 5.5-7.6) among those with asthma. The prevalence of hay fever and/or asthma was 24.7\% (95\% CI 22.9-26.1, Fig. 3). In particular, 5.1\% (95\% CI 4.2-6.1) of the adult population was diagnosed with EAH.

\section{Associations with eczema and EAH}

The prevalence of adult eczema $(19.4 \%$ vs $12.0 \%$, $P<0.001)$ and EAH $(7.1 \%$ vs $3.1 \%, P<0.01)$ was higher in urbanized areas compared with rural areas (Table 1). No gender or ethnic differences were found in the prevalence of eczema and EAH. The prevalence of eczema and EAH showed significant difference among age groups and was highest in the $30-39$ year group $(20.6 \%$ and $8.5 \%$, respectively) ( $P=0.003, P=0.001$, respectively). Prevalence of positive family history of atopy was higher in EAH group than in eczema group (58.9\% vs $44.5 \%, P<0.001)$. There was a significant difference in the prevalence of eczema among the six study areas $(P=0.007)$, but EAH did not vary significantly $(P=0.32)$ (Fig. 4).

Socioeconomic factors that were associated with higher prevalence of adult eczema and EAH are shown in Table 1. In particular, a higher level of education $(P<0.001$, both $)$ and higher family income $(P=0.007$ and $P<0.001$, respectively) were associated with increased prevalence of eczema and EAH. Environmental factors are evaluated in Table 2, which shows that the prevalence of EAH was significantly different depending on heating mode $(P=0.029)$; however, this variation was not seen in eczema $(P=0.073)$. Antibiotic overuse significantly increased the prevalence of EAH ( $9.0 \%$ vs $4.1 \%, P<0.001)$, but did not increase the prevalence of eczema $(P=0.235)$.

The prevalence of eczema was higher in subjects with a higher education level (OR 2.49, 95\% CI 1.55-4.04, $P<0.001$ in medium compared with low level) while medium and high education levels increased the risk of EAH (OR 3.31, 95\% CI 1.83-5.98, $P<0.001$ and OR 5.38, $95 \%$ CI $2.04-14.18, P<0.001)$ as shown by a multivariate logistic regression model. Family history of atopy increased eczema risk 1.39-fold, and increased EAH risk 2.10 -fold ( $P=0.017, P=0.002$ respectively). Antibiotic overuse increased the risk of EAH, but not eczema (OR $1.71, P=0.022$ and $\mathrm{OR} 0.95, P=0.756$, respectively) (Table 3).

\section{Allergen sensitization in adult eczema and EAH}

The aeroallergens sensitization rate was $48.2 \%$ in the eczema group and $41.0 \%$ in the non-eczema subjects $(P=0.018)$. Regarding $\mathrm{EAH}$, the aeroallergen 
Table 1 Demographic characteristics of the eczema and EAH study population

\begin{tabular}{|c|c|c|c|c|c|c|c|}
\hline \multirow[t]{2}{*}{ Variables } & \multicolumn{3}{|l|}{ Eczema } & \multicolumn{3}{|l|}{ EAH } & \multirow[t]{2}{*}{ Total } \\
\hline & No $(n=1766)$ & Yes $(n=330)$ & $P$ & No $(n=1989)$ & Yes $(n=107)$ & $P$ & \\
\hline Age (years), mean $\pm S D$ & $47.94 \pm 14.85$ & $43.32 \pm 14.02$ & 0.001 & $48.22 \pm 13.89$ & $44.99 \pm 13.65$ & $<0.001$ & $47.71 \pm 13.90$ \\
\hline \multicolumn{3}{|l|}{ Gender, n (\%) } & \multirow[t]{3}{*}{0.698} & & & \multirow[t]{3}{*}{0.312} & \\
\hline Male & $713(83.9)$ & $137(16.1)$ & & $812(95.5)$ & $38(4.5)$ & & $850(40.6)$ \\
\hline Female & $1053(84.5)$ & $193(15.5)$ & & $1177(94.5)$ & $69(5.5)$ & & $1246(59.4)$ \\
\hline \multicolumn{3}{|l|}{ Ethnicity, n (\%) } & \multirow[t]{4}{*}{0.811} & & & \multicolumn{2}{|l|}{0.645} \\
\hline Han & $1050(84.3)$ & $195(15.7)$ & & $1182(94.9)$ & $63(5.1)$ & & $1245(59.4)$ \\
\hline Mongolian & $649(84.4)$ & $120(15.6)$ & & $731(95.1)$ & $38(4.9)$ & & $769(36.7)$ \\
\hline Other & $67(81.7)$ & $15(18.3)$ & & $76(92.7)$ & $6(7.3)$ & & $82(3.9)$ \\
\hline \multicolumn{3}{|l|}{ Residence, n (\%) } & \multicolumn{3}{|l|}{$<0.001$} & \multicolumn{2}{|l|}{$<0.001$} \\
\hline Rural & 857 (80.6) & $206(19.4)$ & & $988(92.9)$ & $75(7.1)$ & & $1063(50.8)$ \\
\hline Urban & $907(88.0)$ & $124(12.0)$ & & $999(96.9)$ & $32(3.1)$ & & $1031(49.2)$ \\
\hline \multicolumn{3}{|l|}{ Education level, n (\%) ${ }^{\mathrm{a}}$} & \multicolumn{3}{|l|}{$<0.001$} & \multicolumn{2}{|l|}{$<0.001$} \\
\hline Low & $457(90.5)$ & $48(9.5)$ & & $496(98.2)$ & $9(1.8)$ & & $505(24.1)$ \\
\hline Medium & $796(86.3)$ & $126(13.7)$ & & $893(96.9)$ & $29(3.1)$ & & $922(44.1)$ \\
\hline High & $511(76.7)$ & $155(23.3)$ & & $598(89.8)$ & $68(10.2)$ & & $666(31.8)$ \\
\hline \multicolumn{3}{|l|}{ Marital status, n (\%) } & \multirow[t]{4}{*}{0.411} & & & \multicolumn{2}{|l|}{0.307} \\
\hline Unmarried & $120(80.5)$ & $29(19.5)$ & & $138(92.6)$ & $11(7.4)$ & & $149(7.2)$ \\
\hline Married & $1601(84.6)$ & $291(15.4)$ & & $1801(95.2)$ & $91(4.8)$ & & $1892(90.9)$ \\
\hline Divorced/widowed & 35 (85.4) & $6(14.6)$ & & $38(92.7)$ & $3(7.3)$ & & $41(2.0)$ \\
\hline $\begin{array}{l}\text { Annual family income } \\
(C N Y, \text { mean } \pm S D)^{c}\end{array}$ & $5.1 \pm 4.0$ & $5.7 \pm 5.3$ & 0.007 & $5.1 \pm 4.1$ & $6.5 \pm 4.6$ & 0.001 & $5.2 \pm 4.2$ \\
\hline \multicolumn{3}{|l|}{ BMI $^{d}, n(\%)$} & \multicolumn{3}{|l|}{0.608} & \multicolumn{2}{|l|}{0.409} \\
\hline Lean or healthy & $873(83.7)$ & $170(16.3)$ & & $983(94.2)$ & $60(5.8)$ & & $1043(49.8)$ \\
\hline Overweight & $696(86.3)$ & $129(15.6)$ & & $788(95.5)$ & $37(4.5)$ & & $825(39.4)$ \\
\hline Obese & $196(86.3)$ & $31(13.7)$ & & 217 (95.6) & $10(4.4)$ & & $227(10.8)$ \\
\hline \multicolumn{3}{|l|}{ Family history, n (\%) } & \multirow[t]{3}{*}{$<0.001$} & & & \multicolumn{2}{|l|}{$<0.001$} \\
\hline Positive & $579(32.8)$ & $147(44.5)$ & & $663(33.3)$ & $63(58.9)$ & & $726(35.7)$ \\
\hline Negative & $1187(67.2)$ & $183(55.4)$ & & $1326(66.7)$ & $44(41.1)$ & & $1310(64.3)$ \\
\hline \multicolumn{8}{|c|}{$\begin{array}{l}\text { a Education was categorized as low (received only primary education or no education), medium (finished secondary school or high school) and high (graduated from } \\
\text { college or university). Education status was missing in } 3 \text { cases in this study }\end{array}$} \\
\hline \multicolumn{8}{|c|}{ b Marital status was missing in 14 cases } \\
\hline \multicolumn{8}{|c|}{ ' Family income was calculated as 10,000 RMB/year/ family } \\
\hline
\end{tabular}

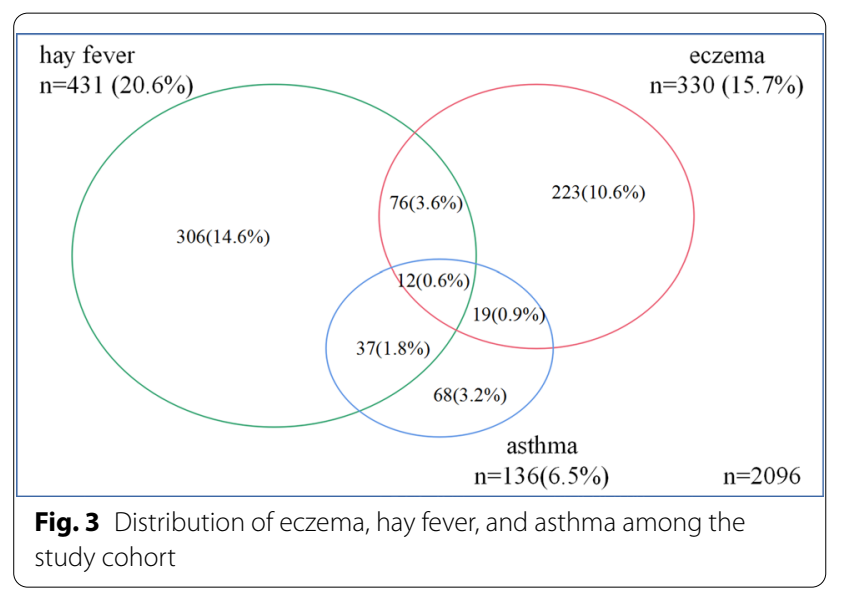

sensitization rate was $53.8 \%$, which was higher than the eczema population $(P<0.001)$. The sensitization rates to 10 aeroallergens are shown in Fig. 5, with the most common being weed pollen sensitization. The positive rate of $\mathrm{Dp}$ was $23.4 \%$ in $\mathrm{EAH}$ and $19.0 \%$ in eczema $(P<0.001)$. The sensitization of $\mathrm{Dp}$ was positively correlated with increasing eczema (OR 1.52, 95\% CI $1.12-2.07, P=0.007)$ and EAH (OR 1.90, 95\% CI 1.193.03, $P=0.007$ ) (Table 4). Allergen sensitization could increase the risk of eczema and EAH which was more obvious with Dp than pollen (OR 1.52 vs 1.29 in eczema and OR 1.90 vs 1.82 in EAH, respectively). 

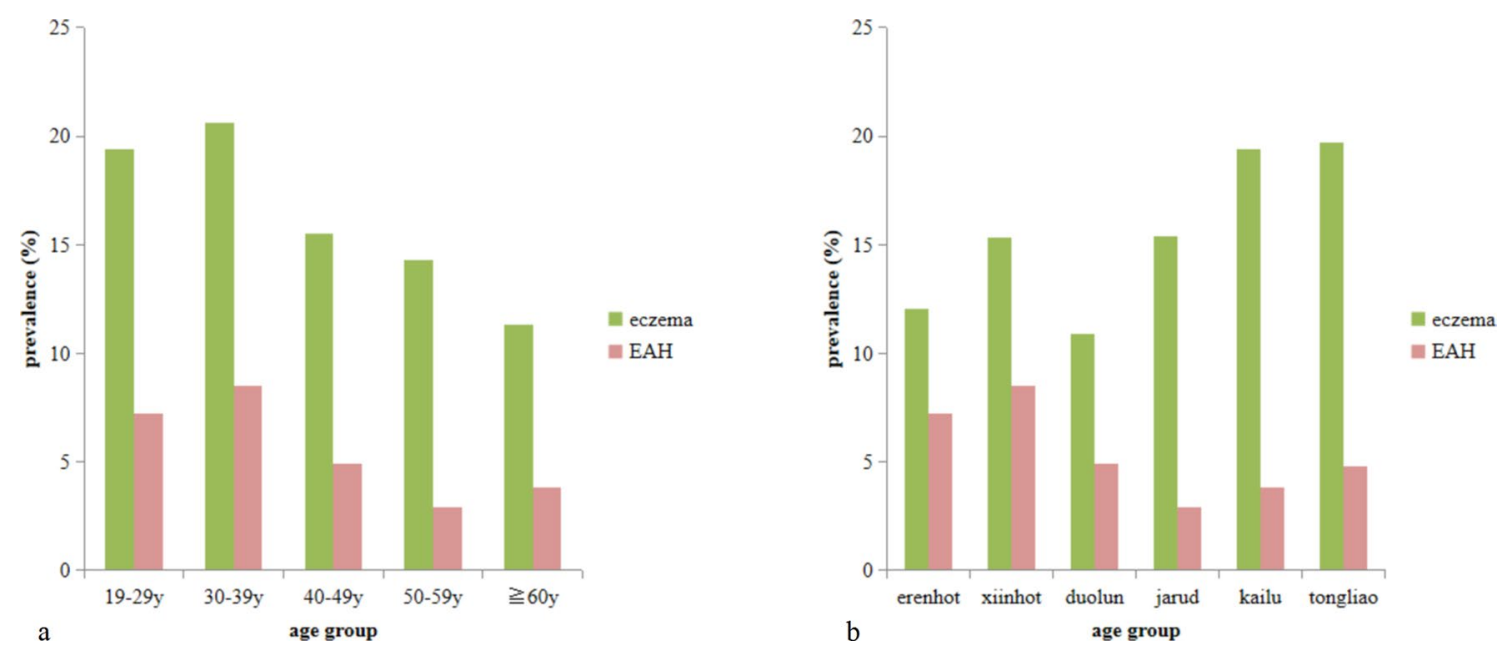

Fig. 4 Variation in eczema and EAH prevalence across different age groups and geographic regions

Table 2 The environmental determinants of the eczema and EAH study population

\begin{tabular}{|c|c|c|c|c|c|c|}
\hline \multirow[t]{2}{*}{ Variables, n (\%) } & \multicolumn{3}{|l|}{ Eczema } & \multicolumn{3}{|l|}{ EAH } \\
\hline & No $(n=1766)$ & Yes $(n=330)$ & $P$ & No $(n=1989)$ & Yes $(n=107)$ & $P$ \\
\hline Pet keeping & & & 0.188 & & & 0.330 \\
\hline No & 1379 (83.7) & $268(16.3)$ & & $1559(94.7)$ & $88(5.3)$ & \\
\hline Yes & $386(86.4)$ & $61(13.6)$ & & $429(96.0)$ & $18(4.0)$ & \\
\hline Smoking habit & & & 0.259 & & & 0.354 \\
\hline Never & $1301(84.5)$ & $238(15.5)$ & & $1455(94.5)$ & $84(5.5)$ & \\
\hline Current & $325(85.1)$ & $57(14.9)$ & & $368(96.3)$ & $14(3.7)$ & \\
\hline Stopped & $117(79.6)$ & $30(20.4)$ & & $140(95.2)$ & $7(4.8)$ & \\
\hline Heating mode & & & 0.073 & & & 0.029 \\
\hline Wood heating & $261(88.8)$ & $33(11.2)$ & & $288(98.0)$ & $6(2.0)$ & \\
\hline Coal heating & $215(84.3)$ & $40(15.7)$ & & $244(95.7)$ & $11(4.3)$ & \\
\hline Central heating & $1206(83.5)$ & $239(16.5)$ & & $1363(94.3)$ & $82(5.7)$ & \\
\hline $\begin{array}{l}\text { Antibiotic overuse ( } \geq 3 \\
\text { times/years) }\end{array}$ & & & 0.235 & & & $<0.001$ \\
\hline No & $1364(85.1)$ & $239(14.9)$ & & 1538 (95.9) & $65(4.1)$ & \\
\hline Yes & $368(82.7)$ & $77(17.3)$ & & $405(91.0)$ & $40(9.0)$ & \\
\hline Daily outdoor activity & & & 0.133 & & & 0.857 \\
\hline$\leq 1 \mathrm{~h}$ & $276(81.9)$ & $61(18.1)$ & & $319(94.7)$ & $18(5.3)$ & \\
\hline $2-3 h$ & $836(83.6)$ & $164(16.4)$ & & $947(94.7)$ & $53(5.3)$ & \\
\hline$\geq 4 \mathrm{~h}$ & $653(86.3)$ & $104(13.7)$ & & $721(95.2)$ & $36(4.8)$ & \\
\hline
\end{tabular}

EAH Eczema with asthma and/or hay fever

The association of allergic diseases with eczema and EAH Allergic disease comorbidity could increase the risk of eczema and EAH (Table 4). In particular, food allergy was associated with eczema (OR 2.86, 95\% CI 2.143.82, $P<0.001$ ) and EAH (OR 2.76, 95\% CI 1.77-4.30, $P<0.001)$. Subjects with two or more combined allergic diseases were at increased risk of having eczema and EAH $(P<0.001)$.

\section{Discussion}

Eczema represents a group of conditions with no standard clinical definition. The diagnosis of adult AD can be challenging since this terminology has been 
Table 3 Common risk factors among subjects with adult eczema and EAH by multivariate logistic regression

\begin{tabular}{|c|c|c|c|c|c|c|}
\hline \multirow[t]{2}{*}{ Variable } & \multicolumn{3}{|c|}{ Eczema } & \multicolumn{3}{|l|}{ EAH } \\
\hline & OR & $95 \% \mathrm{Cl}$ & $P$ value & OR & $95 \% \mathrm{Cl}$ & $P$ value \\
\hline \multicolumn{7}{|c|}{ Age (years), quartile } \\
\hline $1(18-37)$ & 1 & 1 & - & 1 & 1 & - \\
\hline $2(38-47)$ & 1.57 & $1.00-2.46$ & 0.052 & 0.80 & $0.37-1.74$ & 0.579 \\
\hline $3(48-60)$ & 1.58 & $1.01-2.48$ & 0.044 & 0.91 & $0.42-1.98$ & 0.810 \\
\hline $4(\geqq 60)$ & 1.36 & $0.88-2.10$ & 0.169 & 1.46 & $0.64-3.33$ & 0.357 \\
\hline \multicolumn{7}{|l|}{ Residence } \\
\hline Rural & 1 & 1 & - & 1 & 1 & - \\
\hline Urban & 1.39 & $1.01-1.92$ & 0.045 & 1.27 & $0.71-2.27$ & 0.423 \\
\hline \multicolumn{7}{|l|}{ Education level } \\
\hline Low & 1 & 1 & - & 1 & 1 & - \\
\hline Medium & 2.49 & $1.54-4.04$ & $<0.001$ & 3.31 & $1.83-5.98$ & $<0.001$ \\
\hline High & 1.45 & $0.96-2.19$ & 0.078 & 5.38 & $2.04-14.18$ & $<0.001$ \\
\hline \multicolumn{7}{|l|}{$\mathrm{AFl}^{\mathrm{a}}$, quartile } \\
\hline $1(0-2)$ & 1 & 1 & - & 1 & 1 & - \\
\hline $2(3-4)$ & 1.20 & $0.80-1.81$ & 0.386 & 0.90 & $0.46-1.76$ & 0.747 \\
\hline $3(5-7)$ & 1.14 & $0.77-1.67$ & 0.520 & 1.78 & $0.89-3.54$ & 0.104 \\
\hline $4(\geq 8)$ & 1.15 & $0.80-1.64$ & 0.450 & 1.46 & $0.82-2.59$ & 0.199 \\
\hline \multicolumn{7}{|l|}{ Family history } \\
\hline No & 1 & 1 & - & 1 & 1 & - \\
\hline Yes & 1.39 & $1.06-1.82$ & 0.017 & 2.10 & $1.33-3.34$ & 0.002 \\
\hline \multicolumn{7}{|c|}{ Antibiotics use (> 3/year) } \\
\hline No & 1 & 1 & - & 1 & 1 & - \\
\hline Yes & 0.95 & $0.70-1.29$ & 0.756 & 1.71 & $1.08-2.71$ & 0.022 \\
\hline \multicolumn{7}{|l|}{ Heating mode } \\
\hline Wood heating & 1 & 1 & - & 1 & 1 & - \\
\hline Coal heating & 1.36 & $0.86-2.15$ & 0.194 & 0.73 & $0.26-2.06$ & 0.547 \\
\hline Central heating & 1.43 & $0.94-2.18$ & 0.098 & 1.34 & $0.50-3.57$ & 0.561 \\
\hline
\end{tabular}

${ }^{a}$ AFI: annual family income, 10,000 RMB/year

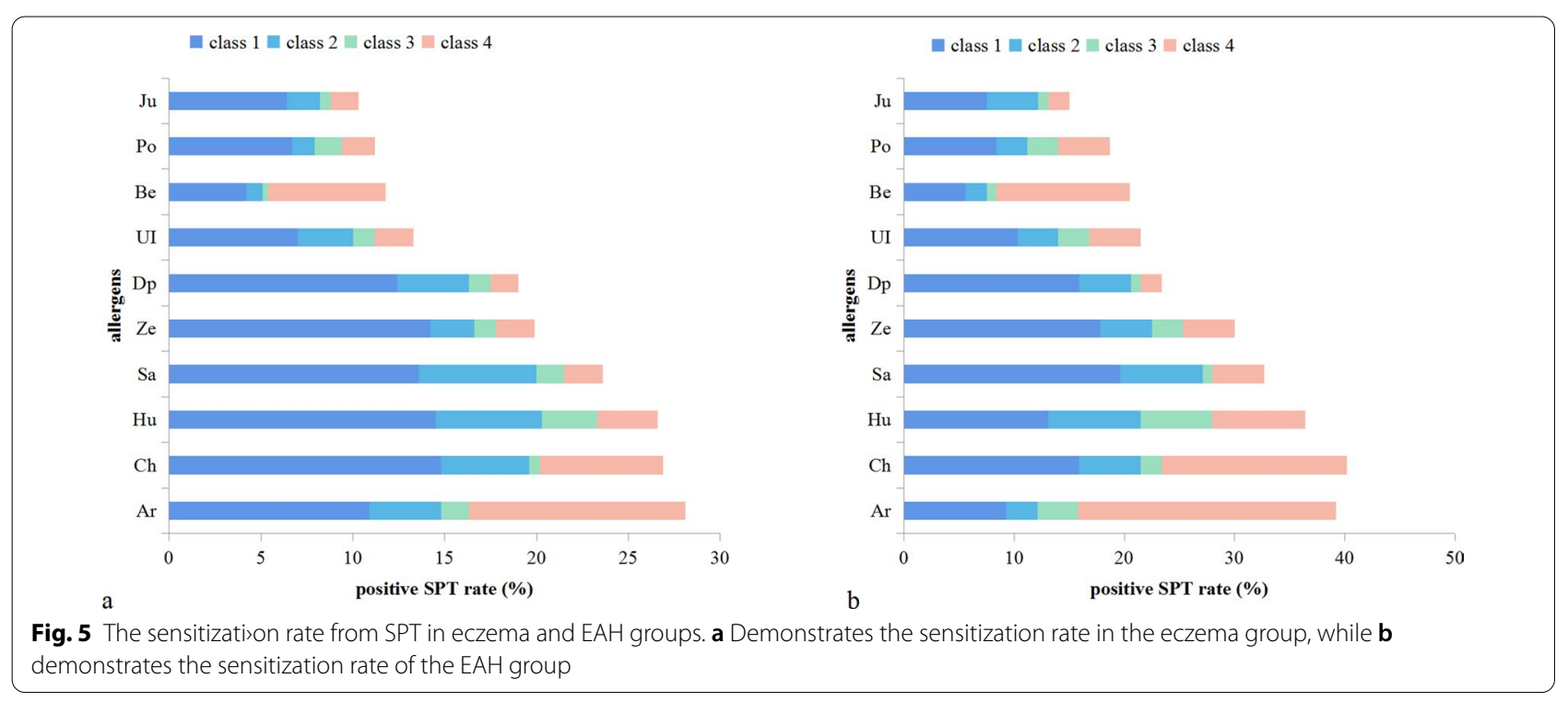


Table 4 The associations of allergic diseases and allergic sensitization with eczema/EAH

\begin{tabular}{|c|c|c|c|c|c|c|c|}
\hline \multirow[t]{2}{*}{ Characteristics } & \multirow[t]{2}{*}{$n$} & \multicolumn{3}{|l|}{ Eczema } & \multicolumn{3}{|l|}{ EAH\# } \\
\hline & & $P$ & OR & $95 \% \mathrm{Cl}$ & $P$ & OR & $95 \% \mathrm{Cl}$ \\
\hline Hay fever & 431 & 0.003 & 1.51 & $1.15-1.98$ & - & - & - \\
\hline Allergic rhinitis & 746 & $<0.001$ & 1.57 & $1.23-1.99$ & $<0.001$ & 22.53 & $11.31-44.89$ \\
\hline Allergic conjunctivitis & 775 & $<0.001$ & 1.57 & $1.24-1.99$ & $<0.001$ & 3.45 & $2.29-5.19$ \\
\hline Asthma & 136 & 0.02 & 1.64 & $1.49-2.08$ & - & - & - \\
\hline Food allergy & 276 & $<0.001$ & 2.86 & $2.14-3.82$ & $<0.001$ & 2.76 & $1.77-4.30$ \\
\hline Drug allergy & 446 & 0.001 & 1.57 & $1.20-2.05$ & 0.047 & 1.55 & $1.01-2.38$ \\
\hline \multicolumn{8}{|l|}{ Disease kinds } \\
\hline One disease & 608 & $<0.001$ & 1.83 & $1.33-2.52$ & 0.001 & 2.17 & $1.35-3.49$ \\
\hline Two diseases & 453 & $<0.001$ & 1.94 & $1.38-2.73$ & $<0.001$ & 5.22 & $3.03-8.98$ \\
\hline$\geq 3$ diseases & 260 & $<0.001$ & 3.66 & $2.56-5.24$ & $<0.001$ & 27.32 & $11.38-65.58$ \\
\hline \multicolumn{8}{|l|}{ SPT positive } \\
\hline Pollen & 843 & 0.035 & 1.29 & $1.02-1.64$ & 0.003 & 1.82 & $1.23-2.68$ \\
\hline HDM & 300 & 0.007 & 1.52 & $1.12-2.07$ & 0.007 & 1.90 & $1.19-3.03$ \\
\hline Pollen + HDM & 883 & 0.015 & 1.34 & $1.06-1.69$ & 0.002 & 1.88 & $1.27-2.79$ \\
\hline
\end{tabular}

${ }^{a}$ Hay fever and asthma were not included when evaluating the associations of allergic diseases and disease kinds with EAH

defined recently and a lack of familiarity and confusion in the definition of the condition persists [6-8]. As in other studies, two definitions were applied in the present study in order to capture all the features of the eczema/AD disease spectrum [17, 22]. The term "eczema" describes a host of ill-defined skin lesions, and encompasses the acute, subacute, and chronic lesions present in $\mathrm{AD}$ [8]. However, use of such an imprecisely defined term as eczema could result in an overestimation of the actual prevalence of $\mathrm{AD}$. In contrast, the term "EAH," while more specific at identifying AD, may result in an underestimation of the prevalence of true AD. In the present study, EAH was assumed to be the proxy indicator of $\mathrm{AD}$.

Adult $\mathrm{AD}$ has distinct clinical characteristics as compared to child-onset AD [6]. Herein, we found a higher prevalence of adult eczema (15.7\%) and EAH (5.1\%) in the northern grassland region of China compared to reports from the US and Europe [17, 22, 29]. The US National Health Interview Survey reported the prevalence of adult eczema as $10.2 \%$ and EAH as $3.2 \%$ [22]. In Italy, the prevalence of eczema and EAH were $8.1 \%$ and $3.4 \%$, respectively, among 10,464 adults [17]. Besides those studies, other studies used different diagnostic criteria, hence the comparability was unreliable. An international, cross-sectional, web-based survey of adults with $\mathrm{AD}$ was performed using modified UK Working Party/ISAAC criteria, and self-report history revealed an overall adult prevalence of $\mathrm{AD}$ of $4.9 \%$ [21]. Although the prevalence was approximately the same as our study, the different survey measurement approach (online vs field-interview) made it hard to compare. A study in Japan noted the prevalence adult AD to be $3 \%$ as defined by the UK Working Party [30]. In Sweden, the prevalence of self-reported eczema as defined by GA2 LEN questionnaire was $11.5 \%$ in 2012 [18]. These surveys provide different accounts of epidemiological features of adult $\mathrm{AD}$ and may improve our understanding of adult $\mathrm{AD}$ in different regions. In China, few surveys have been carried out, and those that have been conducted focused primarily on children. A survey of 11,473 school children from two areas in Guangdong noted the prevalence of eczema and EAH as $25.9 \%$ and $34.1 \%$, respectively [31]. In Shanghai, the prevalence of childhood AD was $8.4 \%$ in 2016 [24]. A nationwide study of adolescents in China found $\mathrm{AD}$ in $2.5 \%$ of subjects [25]. The higher prevalence of adult eczema and $A D$ in our study suggest that $A D$ is increasing in select geographic areas perhaps secondary to elevated pollen in these areas. This study suggested that adult $\mathrm{AD}$ is more common than previously thought. Of note, variation in methods and societal norms may also contribute to study variation. $\mathrm{AD}$ is regarded mainly as a childhood disease and can be outgrown with age. While this may be historically the case, recent studies indicate that $\mathrm{AD}$ is not restricted to children. In Italy, over $50 \%$ of individuals with $\mathrm{AD}$ reported adult onset [17]. This could account, in part, for the high prevalence of AD in our study.

The variation of adult $\mathrm{AD}$ prevalence suggests a role for socioeconomic and environmental factors. No gender difference was found in the present study in contrast to other reports that noted women displayed the studydefined symptomology and clinical presentations $[6$, 29]. Peak prevalence was most frequently observed in 
the 29-39 year age-groups and decreasing prevalence was observed in the $\geq 40$ year age-groups in our study, which is consistent with an international survey of adult AD [21]. Urbanization was associated with an increased prevalence of $\mathrm{AD}$, which is consistent with previous studies $[16,18]$. Taken together, these data suggest that rapid urbanization and industrialization may be involved in the progression of AD. This phenomenon is explained by the hygiene hypothesis, which postulates that environmental antigens in early life is paramount in the development of the immune system [32]. Urbanization and industrialization likely decrease the early exposure to antigens, thus resulting in immune dysfunction and atopic diseases. Another explanation is the increasing exposure to airborne pollution. Pollutants such as $\mathrm{NO}_{2}$, heavy traffic and exposure to diesel exhaust could damage the skin barrier, increase trans-epidermal water loss, and increase the production of IgE [33-36]. Environmental and socioeconomic determinants were analyzed in this study. Several risk factors were found to be associated with eczema/AD, including higher education levels and household incomes. These results suggested an increase of $\mathrm{AD}$ with increasing socioeconomic status both in adults and children [33-36]. Higher socioeconomic status may lead to a reduction in allergen exposure in early life. Place of birth and ethnicity could also contribute to the increasing frequency of $\mathrm{AD}[15,22,37-39]$. Antibiotic overuse was found to be associated with increasing prevalence of allergic rhinitis and asthma in our previous study [40]. In this study, antibiotic overuse was associated with EAH but not eczema, which could be explained by the different subsets of the two diseases. EAH is a typical atopic disease with allergen sensitization contributed to its pathogenesis while eczema was more complicated with less atopic factors involved. Exposure to antibiotics could alter immune balance and favor over-activity that manifests as allergic reaction. In this study, subjects who used wood or coal heating had a higher prevalence of AD than those who used central heating. This effect may be explained by dry air impairing skin barrier function due to central heating and less outdoor activity [32]. A lower prevalence of AD was significantly associated with outdoor humidity, higher temperature, UV light exposure, and less indoor heating [13, 41]. In Inner Mongolia, it is presumed that similar climate factors may influence the prevalence of adult eczema/AD, such as low temperature and arid weather conditions. In brief, younger age, atopy family history, high education level, urbanization, and antibiotic overuse were found to be the risk determinants. Although the prior four are well-known, the impact of antibiotics on $\mathrm{AD}$ is relatively new and should be of concern.
Another key topic addressed in this study was the comorbidities of adult AD. A higher prevalence of other allergic diseases, such as asthma and hay fever, was found in the eczema/AD group compared with the non-eczema group in our study. Thus, AD may play a role in the persistence of asthma or hay fever $[1,3,9]$. Recently, a genome-wide association study [42] of a broad allergic disease phenotype found that 130/136 gene variants were similar in individuals with asthma, hay fever, and $\mathrm{AD}$, thus strongly supporting a genetic aspect to these conditions. Inherited and acquired factors lead to abnormal epidermal structure and function, which could be the beginning of an "allergy march". Studies showed that epigenetic pathways could mediate the gene $\times$ environment interactions and impact the "allergy march" [43]. Epigenetic markers, such as DNA methylation, have been shown to demonstrate a potential for the development of diagnostic tools for allergies [43, 44]. Besides atopic comorbidities, several chronic conditions are associated with adult AD including diabetes, psychiatric diseases, cardiovascular diseases, bone fracture, and hypertension [5, 45-49]. Adult AD should be considered as a systemic disease rather than a skin disease.

One strength of this study was the evaluation of allergic sensitization for adult AD. It is intriguing that the prevalence of $\mathrm{AD}$ is highly affected by aeroallergen sensitization. High pollen concentration, as we reported [26], may contribute to the development of $\mathrm{AD}$ in grassland habitats. Typically, pollen could induce nasal or asthmatic symptoms rather than dermatological symptom. But under extremely high pollen exposure, prevalence of $\mathrm{AD}$ could be high. Interestingly, we found that house dust mite (HDM) allergy had a lower prevalence in subjects from grasslands and in allergic rhinitis subjects. Conversely, HDM allergy was associated with a higher positive SPT rate than tree pollen and grass pollen in AD subjects. Thus, we speculated that two reasons may contribute to this phenomenon. First, the impact of pollen on $\mathrm{AD}$ may be determined by pollen exposure concentrations. In northern grassland region, weed pollen has a higher concentration than tree/grass pollen and could induce more eczema/AD than other type of pollen. Second, HDM allergy was more important in $\mathrm{AD}$ rather than allergic rhinitis or other allergic conditions. Subjects sensitized to HDM has a higher risk of developing eczema/AD despite low concentration exposure. However, whether the prevalence and comorbidities of eczema and EAH could change under lower pollen exposure or higher HDM exposure will need further investigation.

We performed a population-based investigation and analyzed the allergen sensitization of eczema/ 
AD. Efforts to minimize selection bias were made. However, some limitations should be mentioned. First, eczema was defined as self-reported cases of doctordiagnosed "eczema" or "atopic dermatitis". This might overestimate the prevalence of adult eczema due to possible confusion with irritant or contact dermatitis. Second, the prevalence of adult AD may include both childhood persistent AD or adult-onset AD [28]. In this study, we did not list the onset age of AD nor classify the subtype of adult $\mathrm{AD}$. Third, the duration of $\mathrm{AD}$, the severity of $\mathrm{AD}$, and the lesion site of $\mathrm{AD}$ were not mentioned in this study. Thus, it is impossible to provide detailed phenotypic information about adult AD. Finally, food allergen sensitization which was closely related with AD was not included in this study. Thus, assessment of the role of allergy in eczema/AD was incomplete. Further studies concerning the impact of food allergen sensitization, lower pollen exposure or higher HDM exposure on AD should be conducted in the future to understand full aspects of AD.

\section{Conclusions}

The prevalence of adult eczema and AD in the northern grassland area of China was $15.7 \%$ and $5.1 \%$, respectively. Adult eczema/AD was positively associated with increased asthma and hay fever. Significant predictors of adult eczema/AD included age, place of residence, higher education level, higher family income, family history, heating mode, overuse of antibiotics, allergen sensitization, and comorbid atopic diseases.

\section{Acknowledgements}

We thank Professor Guangliang Shan and his team for the design of this study and the processing of the data. We thank Professor Deyun Wang for the advice in drafting of this manuscript. We thank LetPub (http://www.letpub.com) for its linguistic assistance and scientific consultation during the preparation of this manuscript.

\section{Authors' contributions}

XYW and HTW contributed to the design of the study, analysis of data and the drafting of the article. YZ and YLC participated in the survey and the collection of the data. XYW designed the study, analyzed the data and drafted the manuscript. All authors read and approved the final manuscript.

\section{Funding}

Beijing Municipal Administration of Hospitals clinical medicine development of special funding support (ZYLX201826); Beijing Municipal Administration of Hospitals'Youth Programme (QML20180702); Beijing Municipal Administration of Hospitals Incubating Program (PX2017020).

\section{Availability of data and materials}

The datasets used and/or analyzed during the current study are available from the corresponding author on reasonable request.

\section{Declarations}

\section{Ethics approval and consent to participate}

Approval to conduct this study was granted by the institutional review boards of Beijing Shijitan Hospital, and the affiliated hospital of the Beijing Capital Medical University. All participants signed the informed consent.
Consent for publication

Not applicable.

\section{Competing interests}

The authors declare that no conflicts of interest exist.

\section{Author details}

${ }^{1}$ Department of Allergy, Beijing Shijitan Hospital, Capital Medical University, No. 10, Tieyi Road, Haidian District, Beijing 100038, China. ${ }^{2}$ Allergy Center, Beijing Shijitan Hospital, Capital Medical University, Beijing 100038, China.

Received: 8 November 2020 Accepted: 23 February 2021

Published online: 09 March 2021

\section{References}

1. Drucker AM. Atopic dermatitis: burden of illness, quality of life, and associated complications. Allergy Asthma Proc. 2017;38(1):3-8.

2. Napolitano $M$, et al. Adult atopic dermatitis: a review. $G$ Ital Dermatol Venereol. 2016;151(4):403-11.

3. Paller A, et al. Major comorbidities of atopic dermatitis: beyond allergic disorders. Am J Clin Dermatol. 2018;19(6):821-38.

4. Ronnstad A, et al. Association of atopic dermatitis with depression, anxiety, and suicidal ideation in children and adults: a systematic review and meta-analysis. J Am Acad Dermatol. 2018;79(3):448-456.e30.

5. Kauppi S, et al. Adult patients with atopic eczema have a high burden of psychiatric disease: a Finnish nationwide registry study. Acta Derm Venereol. 2019:99(7):647-51.

6. Lee $\mathrm{HH}$, et al. A systematic review and meta-analysis of the prevalence and phenotype of adult-onset atopic dermatitis. J Am Acad Dermatol. 2019;80(6):1526-1532.e7.

7. Mortz CG, et al. Atopic dermatitis from adolescence to adulthood in the TOACS cohort: prevalence, persistence and comorbidities. Allergy. 2015;70(7):836-45

8. Silvestre SJ, Romero-Perez D, Encabo-Duran B. Atopic dermatitis in adults: a diagnostic challenge. J Investig Allergol Clin Immunol. 2017;27(2):78-88

9. Singh $\mathrm{S}$, et al. Allergic rhinitis, rhinoconjunctivitis, and eczema: prevalence and associated factors in children. Clin Respir J. 2018;12(2):547-56.

10. Wang J, et al. Association between breastfeeding and eczema during childhood and adolescence: a cohort study. PLoS ONE. 2017;12(9):e0185066.

11. Silverberg Jl, Simpson EL. Association between severe eczema in children and multiple comorbid conditions and increased healthcare utilization. Pediatr Allergy Immunol. 2013;24(5):476-86.

12. Toledo MF, et al. Changes over time in the prevalence of asthma, rhinitis and atopic eczema in adolescents from Taubate, Sao Paulo, Brazil (2005-2012): relationship with living near a heavily travelled highway. Allergol Immunopathol (Madr). 2016;44(5):439-44.

13. Silverberg J, Hanifin J, Simpson EL. Climatic factors are associated with childhood eczema prevalence in the United States. J Invest Dermatol. 2013;133(7):1752-9.

14. Ballardini N, et al. Development and comorbidity of eczema, asthma and rhinitis to age 12: data from the BAMSE birth cohort. Allergy. 2012;67(4):537-44.

15. Hsu DY, Shinkai K, Silverberg Jl. Epidemiology of eczema herpeticum in hospitalized U.S. children: analysis of a Nationwide Cohort. J Invest Dermatol. 2018;138(2):265-72.

16. Silverberg Jl, Greenland P. Eczema and cardiovascular risk factors in 2 US adult population studies. J Allergy Clin Immunol. 2015;135(3):721-728.e6.

17. Pesce $\mathrm{G}$, et al. Adult eczema in Italy: prevalence and associations with environmental factors. J Eur Acad Dermatol Venereol. 2015;29(6):1180-7.

18. Ronmark EP, et al. Eczema among adults: prevalence, risk factors and relation to airway diseases. Results from a large-scale population survey in Sweden. Br J Dermatol. 2012;166(6):1301-8.

19. Silvestre Salvador JF, Romero-Pérez D, Encabo-Durán B. Atopic dermatitis in adults: a diagnostic challenge. J Invest Allergol Clin Immunol. 2017;27(2):78-88

20. Weidinger S, Novak N. Atopic dermatitis. Lancet. 2016;387(10023):1109-22 
21. Barbarot S, et al. Epidemiology of atopic dermatitis in adults: results from an international survey. Allergy. 2018;73(6):1284-93.

22. Silverberg Jl, Hanifin JM. Adult eczema prevalence and associations with asthma and other health and demographic factors: a US populationbased study. J Allergy Clin Immunol. 2013;132(5):1132-8.

23. Guo Y, et al. Prevalence of atopic dermatitis in Chinese children aged 1-7 ys. Sci Rep. 2016;19(6):29751

24. Xu F, et al. Prevalence of childhood atopic dermatitis: an urban and rural community-based study in Shanghai, China. PLoS ONE. 2012;7(5):e36174.

25. Xiao Y, et al. The prevalence of atopic dermatitis and chronic spontaneous urticaria are associated with parental socioeconomic status in adolescents in China. Acta Derm Venereol. 2019;99(3):321-6.

26. Bastl K, Kmenta M, Berger UE. Defining pollen seasons: background and recommendations. Curr Allergy Asthma Rep. 2018;18(12):73.

27. Wang $X Y$, et al. Prevalence of pollen-induced allergic rhinitis with high pollen exposure in grasslands of northern China. Allergy. 2018;73(6):1232-43.

28. Heinzerling $L$, et al. The skin prick test-European standards. Clin Transl Allergy. 2013;3(1):3.

29. Harrop J, et al. Eczema, atopy and allergen exposure in adults: a population-based study. Clin Exp Allergy. 2007;37(4):526-35.

30. Muto T, et al. Prevalence of atopic dermatitis in Japanese adults. Br J Dermatol. 2003;148(1):117-21.

31. Yang Z, et al. Frequency of food group consumption and risk of allergic disease and sensitization in schoolchildren in urban and rural China. Clin Exp Allergy. 2015;45(12):1823-32.

32. Sacotte R, Silverberg J. Epidemiology of adult atopic dermatitis. Clin Dermatol. 2018;36(5):595-605.

33. Morgenstern $\mathrm{V}$, et al. Atopic diseases, allergic sensitization, and exposure to traffic-related air pollution in children. Am J Respir Crit Care Med. 2008;177(12):1331-7.

34. Eberlein-König B, et al. Influence of airborne nitrogen dioxide or formaldehyde on parameters of skin function and cellular activation in patients with atopic eczema and control subjects. J Allergy Clin Immunol. 1998;101(1 Pt 1):141-3.

35. Shaw TE, et al. Eczema prevalence in the United States: data from the 2003 National Survey of Children's Health. J Invest Dermatol. 2011;131(1):67-73.

36. Silverberg $\mathrm{Jl}$, Paller AS. Association between eczema and stature in 9 US population-based studies. JAMA Dermatol. 2015;151(4):401-9.

37. Deckers $\mid A$, et al. Investigating international time trends in the incidence and prevalence of atopic eczema 1990-2010: a systematic review of epidemiological studies. PLoS ONE. 2012;7(7):e39803.
38. Kim M, et al. Seasonal variation and monthly patterns of skin symptoms in Korean children with atopic eczema/dermatitis syndrome. Allergy Asthma Proc. 2017:38(4):294-9.

39. Petherick ES, et al. Ethnic and socio-economic differences in the prevalence of wheeze, severe wheeze, asthma, eczema and medication usage at 4 years of age: findings from the Born in Bradford birth cohort. Respir Med. 2016;119:122-9.

40. Chen $\mathrm{YL}$, et al. Antibiotic overuse and allergy-related diseases: an epidemiological cross-sectional study in the grasslands of Northern China. Ther Clin Risk Manag. 2019;15:783-9.

41. Sasaki M, et al. Environmental factors associated with childhood eczema: findings from a national web-based survey. Allergol Int. 2016;65(4):420-4.

42. Ferreira MA, et al. Shared genetic origin of asthma, hay fever and eczema elucidates allergic disease biology. Nat Genet. 2017;49(12):1752-7.

43. Potaczek DP, Harb H, Michel S, Alhamwe BA, Renz H, Tost J. Epigenetics and allergy: from basic mechanisms to clinical applications. Epigenomics. 2017;9(4):539-71

44. Alashkar Alhamwe B, Alhamdan F, Ruhl A, Potaczek DP, Renz H. The role of epigenetics in allergy and asthma development. Curr Opin Allergy Clin Immunol. 2020;20(1):48-55.

45. Andersen Y, et al. Adult atopic dermatitis and the risk of type 2 diabetes. J Allergy Clin Immunol. 2017;139(3):1057-9.

46. Silverberg J. Association between adult atopic dermatitis, cardiovascular disease, and increased heart attacks in three population-based studies. Allergy. 2015;70(10):1300-8.

47. Yu SH, Silverberg J. Association between atopic dermatitis and depression in US adults. J Invest Dermatol. 2015:135(12):3183-6.

48. Drucker AM, et al. Atopic dermatitis and risk of hypertension, type 2 diabetes, myocardial infarction and stroke in a cross-sectional analysis from the Canadian Partnership for Tomorrow Project. Br J Dermatol. 2017:177(4):1043-51.

49. Lowe KE, et al. Atopic eczema and fracture risk in adults: a populationbased cohort study. J Allergy Clin Immunol. 2020;145(2):563-571.e8.

\section{Publisher's Note}

Springer Nature remains neutral with regard to jurisdictional claims in published maps and institutional affiliations.

Ready to submit your research? Choose BMC and benefit from:

- fast, convenient online submission

- thorough peer review by experienced researchers in your field

- rapid publication on acceptance

- support for research data, including large and complex data types

- gold Open Access which fosters wider collaboration and increased citations

- maximum visibility for your research: over 100M website views per year

At $B M C$, research is always in progress.

Learn more biomedcentral.com/submissions 